\title{
Use of Risk Calculator in Predicting Postoperative Respiratory Failure in Patients Undergoing Elective/Emergency Surgery at a Tertiary Care Hospital in South India
}

\author{
Surendran Aneeshkumar, Lakshmikanthan Sundararajan ${ }^{1}$ \\ Department of Respiratory Diseases, Bishop Benziger Hospital, Kollam, Kerala, 'Department of Respiratory Diseases, Apollo Hospitals, Chennai, Tamil Nadu, India
}

\section{Abstract}

Background and Objective: Post-operative respiratory failure (PRF) is one of the serious and common complications associated with poor outcomes, prolonged hospital stay and increased health care expenditure. Objective identification of factors leading to PRF would help optimization of patients and improve outcomes. The aim of the study was to assess the risk of PRF in a cohort of patients undergoing surgery using a validated risk calculator score. Methods: The risk calculator score developed by H Gupta et al was used to predict the chances of PRF in patients undergoing elective/emergency surgery at our hospital from January to June 2016. The primary end point was discharge from hospital or death. Results: 100 patients (Male: 74; Female: 26) undergoing elective/emergency surgery were analyzed. Four patients (4\%) died and eleven (11\%) developed respiratory failure. A receiver operating characteristic (ROC) curve with a risk calculator score of 6.30 had $92 \%$ sensitivity and $82 \%$ specificity for predicting PRF. A higher risk score had good correlation with longer hospital stay ( $p=0.001$ ). Interpretation and Conclusion: PRF risk calculator score is a valuable tool in predicting respiratory failure in patients, undergoing elective/ emergency surgery. It can be useful in identifying high risk patients, allowing one to make an informed choice prior to surgery and may also help optimise such patients pre-operatively.

Keywords: Elective/emergency surgery, postoperative respiratory failure, risk calculator

\section{INTRODUCTION}

Postoperative complications can result in severe morbidity and mortality. They could lead to prolonged hospital stay and increased health-care expenditure. ${ }^{[1,2]}$ Postoperative pulmonary complications are among the major contributors to morbidity and mortality in postoperative patients, with incidence ranging from $2 \%$ to $19 \%{ }^{[3]}$

Atelectasis, postoperative pneumonia, acute respiratory distress, and respiratory failure are the most common pulmonary complications in the postoperative setting ${ }^{[4-7]}$ Postoperative respiratory failure (PRF) is perhaps the most serious pulmonary complication defined as an inability to extubate $48 \mathrm{~h}$ post surgery or unexplained intubation/re-intubation within a month of surgery ${ }^{[8]}$ In-hospital mortality of patients with PRF is around $40 \%$ as against $6 \%$ in those without PRF. ${ }^{[7]}$

Attempts have been made to develop predictive models for postoperative pulmonary complications. ${ }^{[9-18]}$ Mazo et al.$^{[19]}$ have

\begin{tabular}{|l|l|}
\hline \multicolumn{2}{|c|}{ Access this article online } \\
\hline Quick Response Code: & Website: \\
\hline & www.ijrconline.org \\
\cline { 2 - 3 } & \\
\hline
\end{tabular}

validated one of these predictive models externally. However, most of these studies have categorized patients as high/intermediate/ low risk instead of having an objective measure, which could potentially lead to significant subjectivity in assessment. ${ }^{[17]} \mathrm{PRF}$ risk calculator ${ }^{[14]}$ is a simple and comprehensive tool which has been shown to quantify the risk of PRF.

\section{Materials and Methods}

This was a prospective observational study, conducted at Apollo Hospitals, Chennai, Tamil Nadu, India, over a period of

Address for correspondence: Dr. Lakshmikanthan Sundararajan, Department of Respiratory Diseases, Apollo Hospitals, 21, Greams Road, Off Greams Lane, Chennai - 600 006, Tamil Nadu, India. E-mail: sundar1967@gmail.com

This is an open access journal, and articles are distributed under the terms of the Creative Commons Attribution-NonCommercial-ShareAlike 4.0 License, which allows others to remix, tweak, and build upon the work non-commercially, as long as appropriate credit is given and the new creations are licensed under the identical terms.

For reprints contact: reprints@medknow.com

How to cite this article: Aneeshkumar S, Sundararajan L. Use of risk calculator in predicting postoperative respiratory failure in patients undergoing elective/emergency surgery at a tertiary care hospital in South India. Indian J Respir Care 2020;9:47-51.

Received: 11-06-2019

Accepted: 15-09-2019

Revised: 04-09-2019 Published: 08-01-2020 
6 months from January to June 2016. Approval was obtained from the institutional ethics committee before commencing the study.

Patients aged 18 years and above, undergoing elective or emergency surgeries, were included in the study. Thoracic surgery patients were excluded because they constitute a high-risk group for PRF and including these patients could skew the results. All patients were followed up until discharge from the hospital or death in the hospital.

For the purpose of this study, respiratory failure was defined as failure to wean from mechanical ventilation within $48 \mathrm{~h}$ after surgery or need to re-intubate during hospital stay. The risk calculator score developed by Gupta et al. ${ }^{[14]}$ was used to predict the risk of PRF. The PRF calculator is freely available online at http://www.surgicalriskcalculator.com/ prf-risk-calculator for download.

The following five variables that comprise this score were recorded:

1. Type of surgery

2. American Society of Anesthesiologists (ASA) score

3. Emergency or elective surgery

4. Preoperative functional status

5. Presence or absence of sepsis prior to surgery.

Each of the above variables has a specific score, which when entered into the calculator gives rise to a predicted percentage risk of PRF.

Basic demographic data including age, sex, and body mass index were collected for all patients. Duration of surgery, length of hospital stay in the postoperative period, duration of mechanical ventilation, and details related to re-intubation were also analyzed. PRF risk expressed as a percentage score was recorded for all patients using the above-mentioned method.

\section{Statistical analysis}

All continuous variables were expressed as mean \pm standard deviation (SD) if they followed a Gaussian distribution. All other nonnormally distributed variables were expressed as median (interquartile range). The normality was assessed by Shapiro-Wilk and one-sample K-S tests. Categorical variables were expressed as percentages. Comparison of nonnormally distributed continuous variables was done by Mann-Whitney U-test. Comparison of categorical variables was done either by Chi-square test or Fisher's exact test based on the number of observations present.

Pearson's correlation coefficient was computed to detect the association between binary continuous variables. Using receiver operating characteristic (ROC) curve and cutoff values, the sensitivity and specificity of PRF risk score were estimated. Data validation and analysis were carried out using SPSS software version 16.0 (SPSS Inc., Chicago, Illinois, USA). $P<0.05$ was considered statistically significant.

\section{RESULTS}

One hundred patients $($ males $=74$; females $=26$ ) were analyzed during the study period. The mean (SD) age of the patients in this study was 55.13 (13.2) years. Basic demographic characteristics are summarized in Table 1.

During the course of the study, 11 (11\%) patients developed respiratory failure and $4(4 \%)$ patients expired. Nearly $19 \%$ of the patients were smokers with median pack-years of 10 ; $28 \%$ of patients had emergency surgery, while $72 \%$ underwent elective surgery. The mean risk calculator score and number of patients developing respiratory failure in smokers/nonsmokers and elective/emergency surgery groups are shown in Table 2. There was no significant difference between the pack-years and risk calculator score.

PRF risk calculator scores and individual variables are shown in Table 3. The highest risk score was found in brain surgery patients (22.1), whereas the lowest score was found in the breast surgery group (0.17). Similarly, the risk of PRF was higher in ASA Class IV patients (17.67), those undergoing emergency surgery (10.22), patients with increased functional dependence (26.78), and those with the presence of septic shock prior to surgery (19.91).

Figure 1 depicts a ROC curve with a risk score of 6.30 having a sensitivity of $92 \%$ and a specificity of $82 \%$ in predicting respiratory failure. Area under the ROC was 92\%. A higher risk calculator score had a positive correlation with the period from surgery to discharge (" $r "=0.330$ and $P=0.001$ ), indicating a prolonged hospital stay in patients with high score [Figure 2].

\begin{tabular}{lc}
\hline Table 1: Demographic characteristics $(\boldsymbol{n = 1 0 0 )}$ & \\
\hline Characteristics & $\boldsymbol{n}(\%)$ \\
\hline Sex & \\
$\quad$ Male & $74(74)$ \\
Female & $26(26)$ \\
Mean age (years) \pm SD & $55.13 \pm 13.2$ \\
BMI & \\
Underweight $<18.5$ & $8(8)$ \\
Normal 18.5-22.9 & $28(28)$ \\
Overweight $23-29.9$ & $52(52)$ \\
Obese $>30$ & $12(12)$ \\
\hline
\end{tabular}

BMI: Body mass index, SD: Standard deviation

\begin{tabular}{lccc}
\hline $\begin{array}{l}\text { Table 2: Risk scores in relation to smoking and type of } \\
\text { surgery }\end{array}$ & $\boldsymbol{n}$ & $\begin{array}{c}\text { Patients who } \\
\text { developed PRF, } \boldsymbol{n}(\%)\end{array}$ & $\begin{array}{c}\text { Mean PRF risk } \\
\text { score } \pm \text { SD }\end{array}$ \\
\hline Variables & 19 & $4(21)$ & $6.32 \pm 7.66$ \\
\hline Smokers & 81 & $7(8.6)$ & $3.80 \pm 5.18$ \\
Nonsmokers & 28 & $9(32)$ & $10.22 \pm 8.03$ \\
Emergency surgery & 72 & $2(2.7)$ & $1.96 \pm 1.62$ \\
Elective surgery & 72 &
\end{tabular}

PRF: Postoperative respiratory failure, SD: Standard deviation 


\begin{tabular}{|c|c|c|}
\hline Variables & Percentage & $\begin{array}{c}\text { PRF risk } \\
\text { calculator score }\end{array}$ \\
\hline \multicolumn{3}{|l|}{ Type of surgery } \\
\hline Anorectal & 7 & 3.59 \\
\hline Abdomina aortic & 2 & 14.8 \\
\hline Bariatric & 1 & 0.88 \\
\hline Brain & 2 & 22.1 \\
\hline Breast & 1 & 0.17 \\
\hline Cardiac & 26 & 3.87 \\
\hline ENT (except thyroid/parathyroid) & 1 & 3.54 \\
\hline Foregut (hepatopancreaticobiliary) & 17 & 2.62 \\
\hline $\begin{array}{l}\text { Gall bladder, appendix, adrenal, and } \\
\text { spleen }\end{array}$ & 6 & 4.03 \\
\hline Hernia (ventral, inguinal, and femoral) & 1 & 1.07 \\
\hline Intestinal & 18 & 4.60 \\
\hline Neck (thyroid and parathyroid) & 1 & 1.41 \\
\hline Obstetrics/gynecology & 3 & 3.08 \\
\hline Orthopedic and nonvascular extremity & - & - \\
\hline Other abdominal & 2 & 8.33 \\
\hline Peripheral vascular & 1 & 3.28 \\
\hline Skin & 3 & 10.23 \\
\hline Spine & - & - \\
\hline Nonesophageal thoracic & 1 & 4.54 \\
\hline Vein & - & - \\
\hline Urology & 7 & 0.94 \\
\hline \multicolumn{3}{|l|}{ ASA class } \\
\hline I & 6 & 0.17 \\
\hline II & 41 & 1.49 \\
\hline III & 45 & 4.97 \\
\hline IV & 82 & 17.67 \\
\hline $\mathrm{V}$ & - & - \\
\hline \multicolumn{3}{|l|}{ Emergency case } \\
\hline Yes & 28 & 10.22 \\
\hline No & 72 & 1.96 \\
\hline \multicolumn{3}{|l|}{ Functional status } \\
\hline Totally dependent & 1 & 26.78 \\
\hline Partially dependent & 6 & 16.46 \\
\hline Totally independent & 93 & 3.25 \\
\hline \multicolumn{3}{|l|}{ Sepsis } \\
\hline SIRS & 1 & 13.33 \\
\hline Septic shock & 2 & 19.91 \\
\hline Sepsis without shock & 5 & 13.68 \\
\hline Without sepsis & 92 & 3.32 \\
\hline
\end{tabular}

PRF: Postoperative respiratory failure, ENT: Ear, nose, and throat SIRS: Systemic inflammatory response syndrome

The mean hospital stay in patients without respiratory failure was 8.4 days compared to 13.7 days in those who developed respiratory failure $(P=0.009)$ [Figure 3].

\section{Discussion}

Postoperative complications, particularly respiratory failure, are associated with increased morbidity and mortality and also increased economic burden due to lengthy hospital stay. Khuri et al. ${ }^{[20]}$ have shown that a postoperative complication

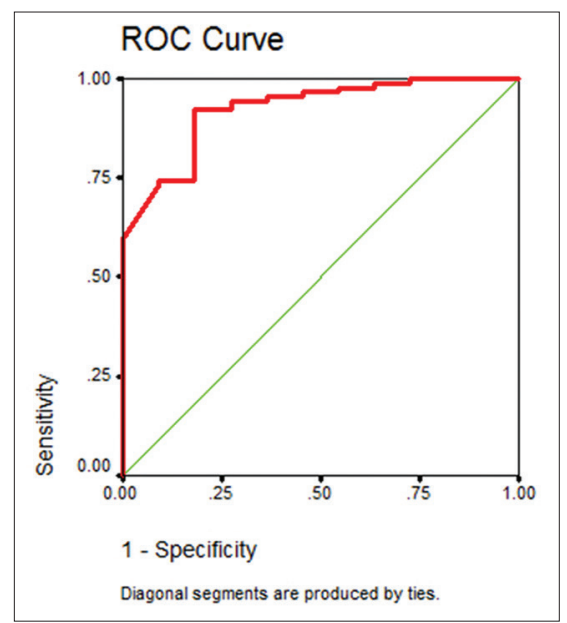

Figure 1: Receiver operating characteristic curve

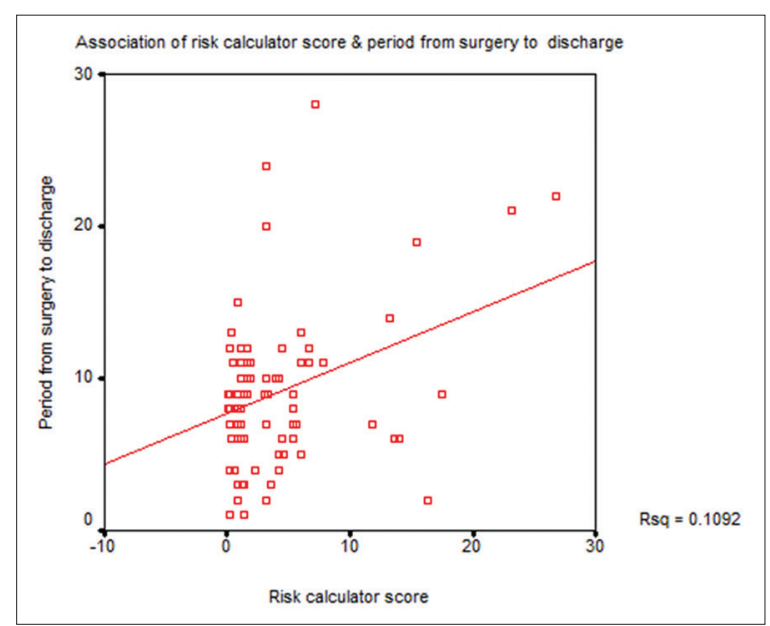

Figure 2: Scatter plot showing the correlation between risk calculator score and period from surgery to discharge

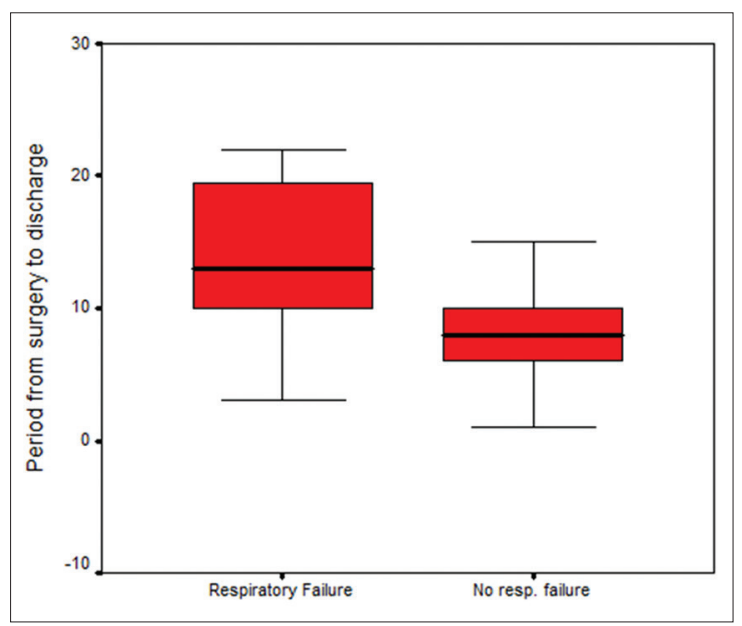

Figure 3: Box plot showing the difference in the period from surgery to discharge in the group with and without respiratory failure

within a month, independent of preoperative risk factors, reduces the median patient survival by $69 \%$. Dimick et al. ${ }^{[21]}$ have observed that postoperative respiratory complications 
Aneeshkumar and Sundararajan: Validity of risk calculator in predicting PRF

contribute to increased hospital stay by 5.5 days, which is at par with our findings (5.3 days). However, factors that could predict PRF have not been studied in many prospective studies.

Managing respiratory complications requires many resources both in terms of human and materials, thereby adding on to the cost burden. In a study by Vonlanthen et al., ${ }^{[22]}$ patients with an uneventful course had a mean cost per case of $\$ 27,946$, but costs increased dramatically with the severity of postoperative complications and reached a mean cost of US\$159,345 for Grade IV complications. This increase in costs, up to five times the cost of a similar operation without complications, was observed for all types of investigated procedures. The reported annual economic burden, in the United States, due to postoperative pulmonary complication is approximately $\$ 3.42$ billion (USD). ${ }^{[23]}$ Prediction of the chances of development of adverse effects may help alleviate the cost burden by taking appropriate precautionary steps.

Most of the publications looking at factors on PRFs were retrospective studies, ${ }^{[10,14]}$ with ours being a prospective study. We have made an attempt to assess the utility of a validated risk calculator score in predicting PRF. Five factors have been found to be important in predicting PRF, namely (i) type of surgery, (ii) ASA score, (iii) emergency/elective procedure, (iv) functional status of patient, and (v) presence or absence of sepsis prior to surgery.

As depicted in our study, the type of surgery has a major impact on the risk score, with the highest values seen in brain, foregut, hepaticopancreatobiliary, and aortic surgeries in descending order. These findings correlate with those of previous studies. ${ }^{[10]}$ Similarly, functional dependence and presence of sepsis prior to surgery are also linked with increased risk scores. Sepsis is one of the major causes for acute respiratory distress syndrome leading to respiratory failure and increased mortality. ${ }^{[24]}$ Hence, correctable factors such as sepsis if appropriately treated prior to surgery can help reduce the incidence of PRF and improve outcomes.

We have shown in this study that using a risk calculator score, one could provide an objective estimate of the risk of PRF in patients preoperatively. A score of $\geq 6.30$ had $92 \%$ sensitivity and $82 \%$ specificity for predicting PRF risk. Higher risk scores are also associated with increased hospital stay, thereby higher costs. Apart from identifying the high-risk population, the risk calculator can also be used as an important tool in obtaining informed consent prior to the procedure. It may also help the operating surgeon to decide on whether the patient will require an intensive care unit care post surgery, or can be managed in the ward. Nevertheless, it may also help the surgeon to make a decision on postponing the elective surgery.

\section{Limitations}

The risk calculator was based on the data available from the National Surgical Quality Improvement Program and although externally validated, may not apply to a different population cohort. Furthermore, the population studied was European, whereas our study was conducted on Asian race. Many other preoperative variables such as pulmonary function tests and other comorbidities such as obstructive sleep apnea and venous thromboembolism were not included. The follow-up period was until discharge from the hospital rather than 1-month post surgery.

However, due to the prospective design of the study and the heterogeneous nature of the patient cohort, the final results could be reliably used in routine clinical practice. The risk calculator score is quite user friendly and could be routinely incorporated into preoperative risk assessment/consultation by pulmonologists and other medical specialists.

\section{Conclusion}

PRF risk calculator is a valuable tool in predicting the risk of PRF in patients undergoing either elective or emergency surgery. This could play an important role in optimizing the preoperative condition of patients and for effective riskstratification.

\section{Financial support and sponsorship \\ Nil.}

\section{Conflicts of interest}

There are no conflicts of interest.

\section{REFERENCES}

1. Fry DE, Pine M, Jones BL, Meimban RJ. Patient characteristics and the occurrence of never events. Arch Surg 2010;145:148-51.

2. Khan NA, Quan H, Bugar JM, Lemaire JB, Brant R, Ghali WA. Association of postoperative complications with hospital costs and length of stay in a tertiary care center. J Gen Intern Med 2006;21:177-80.

3. Fisher BW, Majumdar SR, McAlister FA. Predicting pulmonary complications after nonthoracic surgery: A systematic review of blinded studies. Am J Med 2002;112:219-25.

4. Brooks-Brunn JA. Predictors of postoperative pulmonary complications following abdominal surgery. Chest 1997;111:564-71.

5. McCulloch TM, Jensen NF, Girod DA, Tsue TT, Weymuller EA Jr., Risk factors for pulmonary complications in the postoperative head and neck surgery patient. Head Neck 1997;19:372-7.

6. Ondrula DP, Nelson RL, Prasad ML, Coyle BW, Abcarian H. Multifactorial index of preoperative risk factors in colon resections. Dis Colon Rectum 1992;35:117-22.

7. Money SR, Rice K, Crockett D, Becker M, Abdoh A, Wisselink W, et al. Risk of respiratory failure after repair of thoracoabdominal aortic aneurysms. Am J Surg 1994;168:152-5.

8. Svensson LG, Hess KR, Coselli JS, Safi HJ, Crawford ES. A prospective study of respiratory failure after high-risk surgery on the thoracoabdominal aorta. J Vasc Surg 1991;14:271-82.

9. Arozullah AM, Khuri SF, Henderson WG, Daley J, Participants in the National Veterans Affairs Surgical Quality Improvement Program. Development and validation of a multifactorial risk index for predicting postoperative pneumonia after major noncardiac surgery. Ann Intern Med 2001;135:847-57.

10. Arozullah AM, Daley J, Henderson WG, Khuri SF. Multifactorial risk index for predicting postoperative respiratory failure in men after major noncardiac surgery. The National Veterans Administration Surgical Quality Improvement program. Ann Surg 2000;232:242-53.

11. Ramachandran SK, Nafiu OO, Ghaferi A, Tremper KK, Shanks A, Kheterpal S. Independent predictors and outcomes of unanticipated 
early postoperative tracheal intubation after nonemergent, noncardiac surgery. Anesthesiology 2011;115:44-53.

12. Hua M, Brady JE, Li G. A scoring system to predict unplanned intubation in patients having undergone major surgical procedures. Anesth Analg 2012;115:88-94.

13. Brueckmann B, Villa-Uribe JL, Bateman BT, Grosse-Sundrup M, Hess DR, Schlett CL, et al. Development and validation of a score for prediction of postoperative respiratory complications. Anesthesiology 2013;118:1276-85.

14. Gupta H, Gupta PK, Fang X, Miller WJ, Cemaj S, Forse RA, et al. Development and validation of a risk calculator predicting postoperative respiratory failure. Chest 2011;140:1207-15.

15. Kor DJ, Warner DO, Alsara A, Fernández-Pérez ER, Malinchoc M, Kashyap R, et al. Derivation and diagnostic accuracy of the surgical lung injury prediction model. Anesthesiology 2011;115:117-28.

16. Blum JM, Stentz MJ, Dechert R, Jewell E, Engoren M, Rosenberg AL, et al. Preoperative and intraoperative predictors of postoperative acute respiratory distress syndrome in a general surgical population. Anesthesiology 2013;118:19-29.

17. Canet J, Gallart L, Gomar C, Paluzie G, Vallès J, Castillo J, et al. Prediction of postoperative pulmonary complications in a population-based surgical cohort. Anesthesiology 2010;113:1338-50.

18. McAlister FA, Bertsch K, Man J, Bradley J, Jacka M. Incidence of and risk factors for pulmonary complications after nonthoracic surgery. Am J Respir Crit Care Med 2005;171:514-7.

19. Mazo V, Sabaté S, Canet J, Gallart L, de Abreu MG, Belda J, et al. Prospective external validation of a predictive score for postoperative pulmonary complications. Anesthesiology 2014;121:219-31.

20. Khuri SF, Henderson WG, DePalma RG, Mosca C, Healey NA, Kumbhani DJ. Determinants of long-term survival after major surgery and the adverse effect of postoperative complications. Ann Surg 2005;242:326-41.

21. Dimick JB, Chen SL, Taheri PA, Henderson WG, Khuri SF, Campbell DA Jr., Hospital costs associated with surgical complications: A report from the private-sector national surgical quality improvement program. J Am Coll Surg 2004;199:531-7.

22. Vonlanthen R, Slankamenac K, Breitenstein S, Puhan MA, Muller MK, Hahnloser $\mathrm{D}$, et al. The impact of complications on costs of major surgical procedures: A cost analysis of 1200 patients. Ann Surg 2011;254:907-13.

23. Linde-Zwirble WL, Bloom JD, Mecca RS, Hansell DM. Postoperative pulmonary complications in adult elective surgery patients in the US: Severity, outcomes, and resource use. Crit Care 2010;14 Suppl 1:P210.

24. Stapleton RD, Wang BM, Hudson LD, Rubenfeld GD, Caldwell ES, Steinberg KP, et al. Causes and timing of death in patients with ARDS. Chest 2005;128:525-32. 